\title{
PENGARUH STRATEGI KOMPETITIF TERHADAP INOVASI PERUSAHAAN YANG BERGERAK DI INDUSTRI KERTAS
}

\author{
Winardi Suhardja \\ Program Studi Magister Manajemen Universitas Tarumanegara \\ winardisuhardja16@gmail.com
}

\begin{abstract}
This study aims to analyzing the influence of competitive strategies (cost leadership, differentiation and focusz) on corporate innovation (product, process and administrative innovations) in paper industry. The population in this study were employees of PT. X and PT. Y. The sampling method used was probability sampling and was determined to be 86 respondents of both firms. The analytical method used in this study is the analysis of the Stuctural Equation Model (SEM) with the AMOS program. The results showed that 1) Cost Leadership, Differentiation, Focus proved to have a significant positive effect on Product Innovation, 2) Cost Leadership, Differentiation, Focus proved to have a significant positive effect on Process Innovation, 3) Cost Leadership, Differentiation, Focus proved to have a significant positive effect on Administrative Innovation. For this reason, companies are expected to continue to innovate to increase customer satisfaction by paying attention to their competitive advantages such as maintaining cost advantages, maintaining strong brand identification and focusing on achieving competitive advantage.
\end{abstract}

Abstrak: Penelitian ini bertujuan untuk menganalisis pengaruh strategi kompetitif (Cost Leadership, Differentiation dan Focus) terhadap inovasi perusahaan (Inovasi produk, proses dan administrasi) yang bergerak di industry kertas. Populasi dalam penelitian ini merupakan karyawan PT. X dan PT.Y. Metode pengambilan sampel yang digunakan adalah sampel probabilitas (probability sampling) dan ditetapkan sebanyak 86 responden dari kedua perusahaan. Metode analisis yang akan digunakan dalam penelitian ini adalah analisis Structural Equation Model (SEM) dengan program AMOS. Hasil penelitian menunjukkan bahwa 1) Cost Leadership, Differentiation, Focus terbukti berpengaruh positif signifikan terhadap Inovasi Produk, 2) Cost Leadership, Differentiation, Focus terbukti berpengaruh positif signifikan terhadap Inovasi Proses, 3) Cost Leadership, Differentiation, Focus terbukti berpengaruh positif signifikan terhadap Inovasi Administrasi. Untuk itu, perusahaan diharapkan dapat terus melakukan inovasi untuk meningkatkan kepuasan konsumen dengan memperhatikan keunggulan kompetitif yang dimiliki seperti mempertahankan keunggulan biaya, mempertahankan identifikasi merek yang kuat dan fokus untuk mencapai keunggulan bersaing.

Keywords: Cost Leadership, Differentiation, Focus, Product Innovation, Process Innovation, Administrative Innovation

\section{PENDAHULUAN}

Pada era persaingan bisnis yang semakin ketat ini, setiap perusahaan harus bisa mengantisipasi perubahan dan harapan yang diinginkan oleh pelanggan atas produk yang dihasilkan. Strategi bersaing, tindakan inovasi dan orientasi pasar adalah beberapa solusi yang dapat digunakan untuk mengantisipasi persaingan tersebut (Bakti dan Harun, 2011). Hal ini seperti yang dinyatakan oleh Liana Bratasida selaku Direktur Eksekutif Asosiasi Pulp dan Kertas Indonesia (APKI) bahwa untuk meningkatkan daya saing dan profit dalam industri pulp dan kertas, ada tiga (3) hal yang harus diperhatikan seperti sustainability, inovasi, serta efisiensi sumber daya. 
Inovasi dapat dijadikan sebagai salah satu strategi dalam mencapai kinerja bisnis (Han et al., 1998). Pelanggan umumnya menginginkan produk-produk yang inovatif sesuai dengan keinginan mereka. Kemajuan teknologi yang cepat dan tingginya tingkat persaingan menuntut setiap perusahaan untuk terus menerus melakukan inovasi produk yang pada akhirnya akan meningkatkan keunggulan bersaing pada perusahaan tersebut. Agar perusahaan dapat memiliki keunggulan kompetitif, maka setiap perusahaan dituntut untuk melakukan kreativitas terhadap produk yang mereka pasarkan secara berkala.

Berhubung dengan perkembangan teknologi yang begitu pesat seperti yang telah disebutkan sebelumnya, perusahaan diwajibkan untuk dapat mempertahankan keunggulan kompetitif miliknya dengan berbagai cara agar dapat terus bersaing di dalam pasar dan tidak kalah dengan pesaingnya. Salah satunya melalui inovasi serta kreativitas produk yang dapat meningkatkan kepuasan konsumen, dimana hal tersebut akan mempengaruhi keunggulan kompetitif perusahaan.

Tujuan penelitian ini adalah sebagai berikut:

- Menganalisis pengaruh cost leadership, differentiation dan focus terhadap inovasi produk

- Menganalisis pengaruh cost leadership, differentiation dan focus terhadap inovasi proses

- Menganalisis pengaruh cost leadership, differentiation, dan focus terhadap inovasi administrasi

\section{TELAAH KEPUSTAKAAN}

Bagaimana perusahaan bersaing satu sama lain sekaligus memperoleh dan mempertahankan keunggulan kompetitif merupakan inti dari bahasan manajemen strategik. Tanpa keunggulan kompetitif, perusahaan hanya akan mampu menikmati return normal, yaitu tingkat keuntungan yang dapat diharapkan dari investasi lain yang memiliki tingkat risiko yang sama. Perusahaan yang mampu menciptakan keunggulan kompetitif yang berkesinambungan tidak hanya tergantung pada satu kekuatan yang dimiliki perusahaan saja, namun juga berusaha keras untuk merancang strategi yang mencakup semua aspek. Cara untuk mendapatkan keunggulan kompetitif ini telah dirumuskan oleh Porter (1994) dalam "Generic Strategies", meliputi: keunggulan biaya (cost leadership), diferensiasi (differentiation) dan fokus (focus).

Keunggulan biaya (cost leadership) merupakan hal yang paling jelas dari ketiga strategi generik, di mana dalam suatu perusahaan akan selalu menginginkan menjadi produsen dengan berbiaya rendah dalam industrinya.

Dalam strategi diferensiasi, perusahaan berusaha menjadi unik dalam industrinya di sepanjang beberapa dimensi yang secara umum dihargai oleh pembeli. Perusahaan dihargai dengan harga premi (premium price) karena keunikannya.

Strategi fokus memilih suatu segmen atau kelompok segmen dalam industri bersangkutan dan menyesuaikan strateginya untuk melayani pelanggan dengan mengesampingkan yang lainnya. Dalam strategi fokus, Porter (1994) membaginya menjadi (1) fokus biaya, perusahaan mengusahakan keunggulan biaya dalam segmen sasarannya, dan (2) fokus diferensiasi, perusahaan mengusahakan diferensiasi dalam segmen sasarannya.

Konsep inovasi mempunyai sejarah yang panjang dan pengertian yang berbeda-beda, terutama didasarkan pada persaingan antara perusahaan-perusahaan dan strategi yang berbeda yang diterapkan perusahaan itu sendiri. Damanpour (1991) mendefinisikan inovasi produk sebagai produk atau jasa baru yang diperkenalkan ke pasar untuk memenuhi kebutuhan pasar. Inovasi proses didefinisikan sebagai suatu elemen baru yang diperkenalkan dalam operasi produk dan jasa dalam perusahaan, seperti: materi bahan baku, spesifikasi tugas, mekanisme, maupun peralatan yang digunakan untuk memproduksi produk atau jasa (Damanpour, 1991). Inovasi administrasi berasal dari perubahan struktur organisasi dan proses administrasi, penghargaan dan sistem informasi. 


\section{Hipotesis}

Dalam penelitian ini terdapat tiga hipotesis yang diuji, yaitu:

H1. Strategi Kompetitif (Cost Leadership, Differentiation, Focus) berpengaruh positif terhadap Inovasi Produk.

H2. Strategi Kompetitif (Cost Leadership, Differentiation, Focus) berpengaruh positif terhadap Inovasi Proses.

H3. Strategi Kompetitif (Cost Leadership, Differentiation, Focus) berpengaruh positif terhadap Inovasi Administrasi

\section{METODE PENELITIAN}

Jenis penelitian ini menggunakan metode penelitian eksplanatif. Jenis data yang digunakan terdiri dari data primer dan data sekunder. Data primer dalam penelitian ini bersumber dari penyebaran kuesioner secara langsung kepada karyawan PT. X. dan PT.Y. Metode pemilihan sampel yang digunakan adalah probability sampling dan ditetapkan sebanyak 86 responden. Untuk menentukan besarnya ukuran sampel yang akan diteliti digunakan rumus Slovin (Sevilla, et al, 1984). Teknik penyebaran kuesioner yang dilakukan adalah personally administered questionnaires

Uji Validitas dalam penelitian ini menggunakan Uji Convergent Validitas, yaitu menguji konstruk (indikator) apakah memiliki proporsi variance yang tinggi atau tidak. Evaluasi terhadap reliabilitas model pengukuran menggunakan ukuran reliabilitas komposit (Composite Reliability Measure) dan menggunakan ukuran ekstrak varians (Variance Extracted Measure).

Metode analisis yang akan digunakan dalam penelitian ini adalah analisis Structural Equation Model (SEM) dengan program AMOS. Analisis SEM mampu menganalisis hubungan antara variabel laten dengan variabel indikatornya, hubungan antara variabel laten yang satu dengan variabel laten yang lain, juga mengetahui besarnya kesalahan pengukuran. Disamping hubungan kausal searah, SEM juga memungkinkan untuk menganalisis hubungan dua arah yang seringkali muncul dalam ilmu sosial dan perilaku (Hair et al., 2006).

\section{HASIL PENELITIAN}

Kecocokan Model Keseluruhan

\begin{tabular}{|c|c|c|c|}
\hline Kriteria & $\begin{array}{c}\text { Hasil } \\
\text { Model }\end{array}$ & $\begin{array}{c}\text { Tingkat } \\
\text { kecocokan yang } \\
\text { bisa diterima }\end{array}$ & Evaluasi \\
\hline Chi-square & 110,230 & $\begin{array}{c}\leq 13,14, \text { dimana } \\
\text { Chi Square untuk } \\
\text { df } 86 ; \text { Taraf Sig } \\
5 \%=113,14\end{array}$ & Fit \\
\hline CMIN/DF & 2,448 & Antara $2-5$ & Fit \\
\hline GFI & 0,971 & $>0,90$ & Fit \\
\hline AGFI & 0,915 & $>0,90$ & Fit \\
\hline IFI & 0,932 & $>0,90$ & Fit \\
\hline TLI & 0,935 & $>0,90$ & Fit \\
\hline NFI & 0,927 & $>0,90$ & Fit \\
\hline CFI & 0,915 & $>0,90$ & Fit \\
\hline RMSEA & 0,071 & $<0,08$ & Fit \\
\hline
\end{tabular}

Nilai CMIN/DF sebesar 2,448 menunjukan bahwa model structural di atas baik karena berkisar antara 2 sampai dengan 5 (March and Hocevar, 1985). Nilai Goodness of Fit Index (GFI), Adjusted Goodness of Fit Index (AGFI), IFI, TLI, NFI, dan CFI dengan nilai 
mendekati 1 menunjukkan bahwa model baik. Sementara itu, nilai RMSEA sebesar 0,071 dapat dipertimbangkan model baik. Menurut Hair et al. (2006) disarankan RMSEA bernilai antara 0,03 sampai 0,08 .

1. Hasil Pengujian Hipotesis

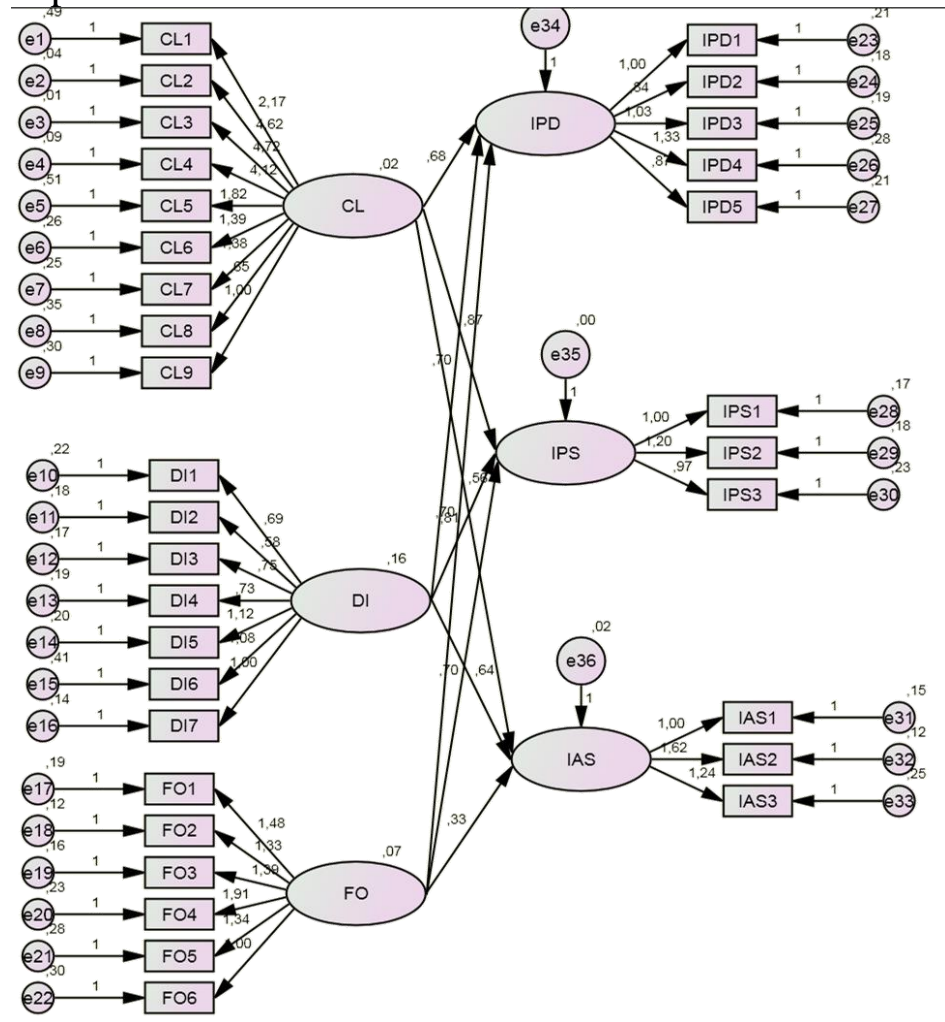

Berdasarkan gambar di atas, selanjutnya dapat dilakukan analisis hipotesis yang dilakukan dengan melihat nilai C.R. (Critical Ratio) yang terdapat pada tabel output AMOS mengenai regression weights yang ditunjukkan pada tabel berikut ini.

\begin{tabular}{|c|cccccc|}
\hline Hipotesis & \multicolumn{3}{|c}{$\begin{array}{c}\text { Hubungan } \\
\text { Variabel }\end{array}$} & Estimate & C.R. & P \\
\hline H1a & IPD & $<---$ & CL & 0,683 & 2,110 & 0,035 \\
\hline H1b & IPD & $<---$ & DI & 0,699 & 5,217 & 0,000 \\
\hline H1c & IPD & $<---$ & FO & 0,697 & 3,107 & 0,002 \\
\hline H2a & IPS & $<---$ & CL & 0,869 & 2,148 & 0,032 \\
\hline H2b & IPS & $<---$ & DI & 0,814 & 5,808 & 0,000 \\
\hline H2c & IPS & $<---$ & FO & 0,703 & 3,034 & 0,002 \\
\hline H3a & IAS & $<---$ & CL & 0,556 & 1,931 & 0,053 \\
\hline H3b & IAS & $<---$ & DI & 0,636 & 4,973 & 0,000 \\
\hline H3c & IAS & $<---$ & FO & 0,331 & 2,235 & 0,025 \\
\hline
\end{tabular}

Untuk mengetahui signifikan tidaknya hubungan antara variabel, maka nilai CR harus lebih besar dari 1,96. Tidak ada ukuran yang pasti mengenai seberapa besar level signifikansi, tetapi umumnya level signifikansi adalah $1 \%, 5 \%$ dan $10 \%$. Jika nilai t yang dihasilkan lebih besar daripada nilai t tabel pada level 5\%, yaitu $\pm 1,960$, maka hubungan antara variabel adalah signifikan (Ghozali, 2005:40).

Berikut adalah pembahasan setiap uji hipotesis berdasarkan hasil pengujian yang dirangkum pada tabel di atas: 
- Hipotesis 1 (H1a)

Nilai Estimate yang diperoleh bernilai positif sebesar 0,683. Hasil tersebut menunjukkan bahwa apabila variabel Cost Leadership mengalami peningkatan sebesar satuan maka Inovasi Produk juga akan mengalami peningkatan sebesar 0,683 (68,3\%). Kemudian dilihat dari nilai CR variabel Cost Leadership sebesar 2,110 dan P-value sebesar 0,035. Hasil ini menunjukan nilai CR tersebut lebih besar dari 1,960 dan P-value lebih kecil dari 0,05. Oleh karena itu Ho ditolak dan Ha diterima artinya Cost Leadership berpengaruh positif terhadap Inovasi Produk. Dengan demikian dapat disimpulkan bahwa Cost Leadership terbukti berpengaruh signifikan positif terhadap Inovasi Produk.

- Hipotesis 1 (H1b)

Nilai Estimate yang diperoleh pada variabel Differentiation bernilai positif sebesar 0,699. Hasil tersebut menunjukkan bahwa apabila variabel Differentiation mengalami peningkatan sebesar satuan maka Inovasi Produk juga akan mengalami peningkatan sebesar 0,699 (69,9\%). Sementara itu, nilai CR yang diperoleh sebesar 5,217 dan P-value sebesar 0,000. Nilai CR tersebut lebih besar dari 1,960 dan P-value lebih kecil dari 0,05. Oleh karena itu Ho ditolak dan Ha diterima artinya Differentiation berpengaruh positif terhadap Inovasi Produk. Dengan demikian dapat disimpulkan bahwa Differentiation terbukti berpengaruh signifikan positif terhadap Inovasi Produk.

- Hipotesis 1 (H1c)

Nilai Estimate yang diperoleh pada variabel Focus bernilai positif sebesar 0,697. Hasil tersebut menunjukkan bahwa apabila variabel Focus mengalami peningkatan sebesar satuan maka Inovasi Produk juga akan mengalami peningkatan sebesar 0,697 (69,7\%). Sementara itu, nilai CR yang diperoleh sebesar 3,107 dan P-value sebesar 0,002. Nilai CR tersebut lebih besar dari 1,960 dan P-value lebih kecil dari 0,05. Oleh karena itu Ho ditolak dan Ha diterima artinya Focus berpengaruh positif terhadap Inovasi Produk. Dengan demikian dapat disimpulkan bahwa Focus terbukti berpengaruh signifikan positif terhadap Inovasi Produk.

- Hipotesis 2 (H2a)

Nilai Estimate yang diperoleh bernilai positif sebesar 0,869. Hasil tersebut menunjukkan bahwa apabila variabel Cost Leadership mengalami peningkatan sebesar satuan maka Inovasi Proses juga akan mengalami peningkatan sebesar 0,869 (86,9\%). Kemudian dilihat dari nilai CR variabel Cost Leadership sebesar 2,148 dan P-value sebesar 0,032. Hasil ini menunjukan nilai CR tersebut lebih besar dari 1,960 dan P-value lebih kecil dari 0,05. Oleh karena itu Ho ditolak dan Ha diterima artinya Cost Leadership berpengaruh positif terhadap Inovasi Proses. Dengan demikian dapat disimpulkan bahwa Cost Leadership terbukti berpengaruh signifikan positif terhadap Inovasi Proses.

- Hipotesis 2 (H2b)

Nilai Estimate yang diperoleh pada variabel Differentiation bernilai positif sebesar 0,814 . Hasil tersebut menunjukkan bahwa apabila variabel Differentiation mengalami peningkatan sebesar satuan maka Inovasi Proses juga akan mengalami peningkatan sebesar 0,814 (81,4\%). Sementara itu, nilai CR yang diperoleh sebesar 5,808 dan $P$-value sebesar 0,000. Nilai CR tersebut lebih besar dari 1,960 dan $P$-value lebih kecil dari 0,05. Oleh karena itu Ho ditolak dan Ha diterima artinya Differentiation berpengaruh positif terhadap Inovasi Proses. Dengan demikian dapat disimpulkan bahwa Differentiation terbukti berpengaruh signifikan positif terhadap Inovasi Proses.

- Hipotesis 2 (H2c)

Nilai Estimate yang diperoleh pada variabel Focus bernilai positif sebesar 0,703. Hasil tersebut menunjukkan bahwa apabila variabel Focus mengalami peningkatan sebesar satuan maka Inovasi Proses juga akan mengalami peningkatan sebesar 0,703 (70,3\%). Sementara itu, nilai CR yang diperoleh sebesar 3,034 dan P-value sebesar 0,002. Nilai CR tersebut lebih besar dari 1,960 dan $P$-value lebih kecil dari 0,05. Oleh 
karena itu Ho ditolak dan Ha diterima artinya Focus berpengaruh positif terhadap Inovasi Proses. Dengan demikian dapat disimpulkan bahwa Focus terbukti berpengaruh signifikan positif terhadap Inovasi Proses.

- Hipotesis 3 (H3a)

Nilai Estimate yang diperoleh variabel Cost Leadership bernilai positif sebesar 0,556. Hasil tersebut menunjukkan bahwa apabila variabel Cost Leadership mengalami peningkatan sebesar satuan maka Inovasi Administrasi juga akan mengalami peningkatan sebesar $0,556(55,6 \%)$. Kemudian dilihat dari nilai CR variabel Cost Leadership sebesar 1,931 dan $P$-value sebesar 0,053. Hasil ini menunjukan nilai CR tersebut hanya sedikit lebih kecil dari 1,960 dan $P$-value hanya sedikit lebih besar dari 0,05. Oleh karena itu Ho ditolak dan Ha diterima artinya Cost Leadership berpengaruh positif terhadap Inovasi Administrasi. Dengan demikian dapat disimpulkan bahwa Cost Leadership terbukti berpengaruh signifikan positif terhadap Inovasi Administrasi.

- Hipotesis 3 (H3b)

Nilai Estimate yang diperoleh pada variabel Differentiation bernilai positif sebesar 0,636. Hasil tersebut menunjukkan bahwa apabila variabel Differentiation mengalami peningkatan sebesar satuan maka Inovasi Administrasi juga akan mengalami peningkatan sebesar 0,636 (63,6\%). Sementara itu, nilai CR yang diperoleh sebesar 4,973 dan P-value sebesar 0,000. Nilai CR tersebut lebih besar dari 1,960 dan P-value lebih kecil dari 0,05. Oleh karena itu Ho ditolak dan Ha diterima artinya Differentiation berpengaruh positif terhadap Inovasi Administrasi. Dengan demikian dapat disimpulkan bahwa Differentiation terbukti berpengaruh signifikan positif terhadap Inovasi Administrasi.

- Hipotesis 3 (H3c)

Nilai Estimate yang diperoleh pada variabel Focus bernilai positif sebesar 0,331. Hasil tersebut menunjukkan bahwa apabila variabel Focus mengalami peningkatan sebesar satuan maka Inovasi Administrasi juga akan mengalami peningkatan sebesar $0,331(33,1 \%)$. Sementara itu, nilai CR yang diperoleh sebesar 2,235 dan $P$-value sebesar 0,025 . Nilai CR tersebut lebih besar dari 1,960 dan P-value lebih kecil dari 0,05. Oleh karena itu Ho ditolak dan Ha diterima artinya Focus berpengaruh positif terhadap Inovasi Administrasi. Dengan demikian dapat disimpulkan bahwa Focus terbukti berpengaruh signifikan positif terhadap Inovasi Administrasi.

Berdasarkan hasil pengujian hipotesis yang telah dilakukan, ditemukan bahwa Cost Leadership, Differentiation, dan Focus berpengaruh terhadap inovasi produk, inovasi proses dan inovasi administrasi. Hasil ini sejalan dengan hasil penelitian Fathali (2016) bahwa Cost Leadership, Differentiation, dan Focus berpengaruh signifikan positif terhadap strategi inovasi. Hasil ini juga sejalan dengan Porter (1998), (Hage dan Hollingsworth, 2000; Wong dan He, 2003; Chuang, 2005; Mavondo et al., 2005) bahwa dimensi strategi kompetitif mempengaruhi dimensi inovasi perusahaan manufaktur pada industri otomotif di Iran. Hasil ini mendukung pernyataan (Greve, 2003; Mavondo et al., 2005) bahwa perusahaan harus mempertimbangkan strategi kompetitif ketika menjelaskan faktor-faktor yang mempengaruhi strategi inovasi. Ini sejalan dengan argument Goktan (2005) dan Jiménez-Jimenez et al. (2008) bahwa strategi bersaing yang sesuai sangat penting untuk inovasi perusahaan.

\section{KESIMPULAN}

Berdasarkan hasil dan pembahasan yang telah diperoleh pada penelitian, maka dapat diperoleh kesimpulan sebagai berikut:

- Cost Leadership, Differentiation, Focus terbukti berpengaruh positif signifikan terhadap Inovasi Produk. Pengaruh positif menunjukkan bahwa semakin baik strategi kompetitif 
yang dilakukan, maka semakin tinggi inovasi produk yang dihasilkan oleh PT. X dan PT. Y

- Cost Leadership, Differentiation, Focus terbukti berpengaruh positif signifikan terhadap Inovasi Proses. Pengaruh positif menunjukkan bahwa semakin baik strategi kompetitif yang dilakukan, maka semakin tinggi inovasi proses yang dihasilkan oleh PT. X dan PT. Y

- Cost Leadership, Differentiation, Focus terbukti berpengaruh positif signifikan terhadap Inovasi Administrasi. Pengaruh positif menunjukkan bahwa semakin baik strategi kompetitif yang dilakukan, maka semakin tinggi inovasi administrasi yang dihasilkan oleh PT. X dan PT. Y

Perusahaan diharapkan dapat terus melakukan inovasi untuk meningkatkan kepuasan konsumen dengan memperhatikan strategi kompetitif yang dimiliki seperti mempertahankan keunggulan biaya (Cost Leadership), mempertahankan identifikasi merek yang kuat (Differentiation) dan fokus (Focus) untuk mencapai keunggulan bersaing (competitive advantages).

\section{DAFTAR PUSTAKA}

Bakti, Sukma dan Harun, Harniza. 2011. Pengaruh Orientasi Pasar Dan Nilai Pelanggan Terhadap Kinerja Pemasaran Penerbangan Lion Air. Jurnal Manajemen Pemasaran Modern, ISSN 2085-0972, 1-15

Chuang, L., 2005. An empirical study of the construction of measuring model for organizational innovation in Taiwanese high-tech enterprises. Journal of American Academy of Business, 9(2): 299-304.

Damanpour, F. 1991. Organizational Innovation: A Meta-Analysis of Effects of Determinants and Moderators. Academy of Management Journal. 34, 3: 555-590.

Goktan, A.B., 2005. The role of strategy in the innovation process: A stage approach. Unpublished Ph.D Dissertation, University of North Texas.

Greve, H.R., 2003. A behavioral theory of R\&D expenditures and innovations: Evidence from shipbuilding. Academy of Management Journal, 46(6): 685-702.

Hage, J. and J.R. Hollingsworth, 2000. A strategy for the analysis of idea innovation networks and institutions. Organizational Studies, 21(5): 971-1004.

Hair, J.F., R.E. Anderson, R.L. Tathan and W.C. Black, 1995. Multivariate data analysis with readings. 4th Edn. Englewood Cliffs, NJ: Prentice-Hall.

Han et al. 1998. Market Orientation and Organizational Performance: Is Innovation a missing link? Journal of Marketing, 4: 30-45.

Jiménez-Jimenez, D., R. Sanz Valle and M. Hernandez-Espallardo, 2008. Fostering innovation. European Journal of Innovation Management, 11(3): 389 - 412.

Mavondo, F.T., J. Chimhanzi and J. Stewart, 2005. Learning orientation and market orientation: Relationship with innovation, human resource practices and performance. European Journal of Marketing, 39(11): 1235-1263.

Porter, Michael E. 1994. What is strategy?. Harvard Business Review, Nov-Dec, pp 61- 78.

Sevilla, Consuelo et, al. 1984. Pengantar Metode Penelitian. Jakarta : Universitas Indonesia Press.

Wong, P.K. and Z.L. He, 2003. The moderating effect of a firm ${ }^{\text {ee }}$ internal climate for innovation on the impact of public R\&D support programs. International Journal of Entrepreneurship and Innovation Management, 3(5/6): 525-545. 
